\title{
COVID-19 Knowledge, Perception, Preventive Measures, Stigma, and Mental Health Among Healthcare Workers in Three Sub-Saharan African Countries: A Phone Survey
}

\author{
Nega Assefa, ${ }^{1 *} \dagger$ Abdramane Soura, ${ }^{2} \dagger$ Elena C. Hemler, ${ }^{3}$ Michelle L. Korte, ${ }^{3}$ Dongqing Wang, ${ }^{3}$ Yasir Y. Abdullahi, ${ }^{4}$ \\ Bruno Lankoande, ${ }^{2}$ Ourohiré Millogo, ${ }^{5}$ Angela Chukwu, ${ }^{6}$ Firehiwot Workneh, ${ }^{7}$ Ali Sie, ${ }^{5}$ Yemane Berhane, ${ }^{7}$ Till Baernighausen, ${ }^{38}$ \\ Ayoade Oduola, ${ }^{9} \ddagger$ and Wafaie W. Fawzi, ${ }^{31011 *} \ddagger$ \\ ${ }^{1}$ College of Health and Medical Sciences, Haramaya University, Harar, Ethiopia; ${ }^{2}$ Institut Supérieur des Sciences de la Population, University of \\ Ouagadougou, Ouagadougou, Burkina Faso; ${ }^{3}$ Department of Global Health and Population, Harvard T.H. Chan School of Public Health, Harvard \\ University, Boston, Massachusetts; ${ }^{4}$ Jegula Hospital, Harar, Ethiopia; ${ }^{5}$ Nouna Health Research Center, Nouna, Burkina Faso; ${ }^{6}$ Department of \\ Statistics, University of Ibadan, Ibadan, Nigeria; ${ }^{7}$ Department of Epidemiology and Biostatics, Addis Continental Institute of Public Health, Addis \\ Ababa, Ethiopia; ${ }^{8}$ Heidelberg Institute of Global Health, University of Heidelberg, Heidelberg, Germany; ${ }^{9}$ University of Ibadan Research Foundation, \\ University of Ibadan, Ibadan, Nigeria; ${ }^{10}$ Department of Nutrition, Harvard T.H. Chan School of Public Health, Harvard University, Boston, \\ Massachusetts; ${ }^{11}$ Department of Epidemiology, Harvard T.H. Chan School of Public Health, Harvard University, Boston, Massachusetts
}

\begin{abstract}
The coronavirus disease 2019 (COVID-19) pandemic is an unprecedented public health crisis globally. Understanding healthcare providers' (HCPs') knowledge and perceptions of COVID-19 is crucial to identifying effective strategies to improve their ability to respond to the pandemic in sub-Saharan Africa. A phone-based survey of 900 HCPs in Burkina Faso, Ethiopia, and Nigeria (300 per country) was conducted to assess knowledge, perceptions, COVID-19 prevention measures, stigma, and mental health of HCPs. Modified Poisson regression models were used to evaluate predictors of knowledge, perceptions, and prevention measures; adjusted risk ratios (ARRs) and 95\% confidence intervals (Cls) were calculated. Three-fourths of the HCPs had adequate knowledge, and over half had correct perceptions of risk and high levels of self-reported prevention measures. The majority of the HCPs (73.7\%) reported self-perceived social stigma. There was relatively low prevalence of depression (6.6\%), anxiety (6.6\%), or psychological distress (18\%). Compared with doctors, being a nurse was associated with lower levels of knowledge (ARR: 0.83; 95\% $\mathrm{Cl}: 0.77-0.90)$ and was also negatively associated with having correct perceptions toward COVID-19 (AOR: 0.82; $95 \%$ $\mathrm{Cl}$ : 0.73-0.92). HCPs treating COVID-19 patients had higher likelihood of having high levels of prevention measures (AOR: 1.37; 95\% Cl: 1.23-1.53). Despite high levels of knowledge among HCPs in sub-Saharan Africa, there is a need to improve COVID-19 perceptions and compliance with prevention measures as well as address social stigma toward HCPs to better ensure their safety and prepare them to deliver health services.
\end{abstract}

\section{INTRODUCTION}

The coronavirus disease 2019 (COVID-19) pandemic is an unmatched crisis and challenge for all nations. ${ }^{1}$ This highly infectious illness has exposed division, distrust, inequality, and trade tensions and, backed up by misinformation, spread across the world like a wildfire. ${ }^{2,3}$ The universal confusion from inaccurate information has been made worse by the speed of the progression and novelty of the virus, which has made it challenging to mitigate the consequences of the pandemic. ${ }^{4,5}$

COVID-19 is an impending danger for countries in subSaharan Africa (SSA) because its mitigation measures may have disastrous consequences given widespread poverty, fragile health systems, and a high prevalence of malnutrition, HIV, tuberculosis, and other comorbidities. ${ }^{6,7}$ At the beginning of the outbreak, many experts feared COVID-19 would be disastrous for SSA countries, though recent reports indicate that much of the continent has been spared these consequences. ${ }^{8}$ As of August 15, 2020, more than two million established COVID-19 cases and 50,000 deaths were reported on the continent, with 48,665 cases total in Nigeria, 27,242 cases in Ethiopia, and 1,237 in Burkina Faso. ${ }^{9,10}$ These figures account for a relatively small amount of global infections and an even smaller proportion of deaths. ${ }^{11}$ This could be the result of

\footnotetext{
* Address correspondence to Nega Assefa, Bote Street, Harar Campus, SGS building, Harar, Ethiopia, E-mail: negaassefa@yahoo.com or Wafaie W. Fawzi, 665 Huntington Avenue, Building 1, Room 1102, Boston, MA 02115, E-mail: mina@hsph.harvard.edu.

†These authors contributed equally as first authors.

$\ddagger$ These authors contributed equally as last authors.
}

limited testing and reporting facilities. It may also reflect the relatively lower incorporation of some African countries in the world economy and the earlier prevention measures many African countries imposed. ${ }^{12}$

Healthcare providers (HCPs) are fighting at the forefront of the COVID-19 pandemic and are at risk due to potential exposure to COVID-19 patients. The International Council of Nurses determined that more than 230,000 HCPs were infected, and 600 nurses had lost their lives globally. ${ }^{13}$ The WHO reported that up to 100,000 HCPs in African countries might have been infected with COVID-19; however, this is likely underestimated. ${ }^{14}$

Poor knowledge of COVID-19 among HCPs leads to delayed diagnosis and shapes their perceptions of the pandemic, preventive measures taken, and infection control practices. ${ }^{15}$ For that reason, the WHO has issued several guidelines, online courses, and training to raise awareness, prevention, and control of COVID-19 among HCPs. ${ }^{16,17}$ Even though COVID-19 has offered some opportunities for HCPs to learn new skills, improve teamwork and team spirit, and increase handwashing and other preventive practices, it has also resulted in societal stigma and discrimination. ${ }^{18}$ Despite their well-deserved rewards, there are numerous reports of social stigma and isolation toward HCPs. ${ }^{19}$ There have been reports that HCPs practicing in informal settlements had trouble providing health services due to fear and stigmatization after COVID-19 exposure. ${ }^{20}$ Additionally, the psychological effects ${ }^{18}$ of the pandemic and mental health risks among HCPs are important issues to address. ${ }^{19}$

Very few studies have examined knowledge, prevention, and management of COVID-19 among HCPs. Understanding HCPs' COVID-19 knowledge, perceptions, and practices is 
crucial to identify effective strategies to contain the virus and safeguard HCPs' physical and mental health in SSA. Identifying gaps in knowledge, perceptions, and preventive measures will help guide interventions to improve HCPs' ability to respond to the pandemic. Therefore, using a novel mobile survey platform, this study aimed to explore the knowledge, perceptions, and preventive practices of HCPs toward COVID-19 prevention and management across three sub-Saharan African countries.

\section{MATERIALS AND METHODS}

Study settings. This study was conducted in three subSaharan African countries: Burkina Faso, Ethiopia, and Nigeria. Healthcare workers, including nurses and physicians, were recruited in urban areas of each country (Ouagadougou in Burkina Faso, Addis Ababa in Ethiopia, and Ibadan and Lagos in Nigeria). The study rationale, sampling strategies, and the use of computer-assisted telephone interviewing technology in the study are described in detail elsewhere. ${ }^{21}$

Study design. This study was part of a planned repeated phone survey for HCPs in urban settings. The phone numbers of the HCPs were identified from lists provided by professional associations and health facilities in each country. Data collectors conducted interviews from virtual call centers using standardized electronic questionnaires. Professionals that exclusively practice medicine or nursing were recruited for the study. Each interview lasted 20-40 minutes. The study included 300 HCPs in each country (900 in total). From the overall lists of providers, we aimed to select $500 \mathrm{HCPs}$ from each country to allow for a $60 \%$ nonresponse rate, but higher rates of nonresponse in some countries led us to select additional HCPs from the sampling frames in some sites to reach the target sample size.

This survey was approved by all necessary ethical review boards in each country, including the Harvard T.H. Chan School of Public Health Institutional Review Board, Nouna Health Research Center Ethical Committee and National Ethics Committee in Burkina Faso, the Institutional Ethical Review Board of Addis Continental Institute of Public Health in Ethiopia, and the University of Ibadan Research Ethics Committee and National Health Research Ethics Committee in Nigeria. All research staff members were trained on study procedures, including screening, consent, enrollment, and data collection, emphasizing confidentiality and safeguarding HCPs' rights and well-being. Experts translated the consent script and the surveys into the local languages of each respective country. The data collectors obtained verbal informed consent from each participant prior to beginning the interview.

Data analysis. The HCPs' responses were analyzed for each survey question by summarizing and computing scores within each country. The full questionnaire administered to HCPs is published elsewhere ${ }^{21}$ and included several sections. The knowledge section included 15 questions that all elicited a yes or no response about the pandemic's reality, symptoms, prevention, and control of COVID-19. The correct answer was counted as 1 point, and the incorrect/unknown answer was 0 points. Knowledge was analyzed at the correct itemby-item rate and a multi-dimensional knowledge score was calculated by summing up the items. The total points scored by each individual ranged between 0 and 15 . Adequate knowledge toward COVID-19 was defined as a score $\geq$ of 13 , moderate knowledge as a score between 7 and 12, and insufficient knowledge as a score of 6 or lower. ${ }^{22-25}$
The perception domain included 10 questions regarding facts and myths about COVID-19. The questions were also modified to suit the study area and settings appropriate for COVID-19. Four questions were related to the control of COVID-19, three questions were related to the transmission of the virus, one question was related to perceptions of preventive measures of COVID-19, and one question was related to treatment availability for COVID-19. A correct answer was counted as 1 point, and the incorrect/unknown answer got 0 points. The perceptions were first analyzed at the correct item-by-item rate. Then, the mean aggregated perception score was calculated by summing up the items. Each individual's total points ranged between 0 and 10, with a higher score indicating a correct perception toward COVID-19. ${ }^{22-26}$

The practice section was comprised of 10 questions about HCPs' experience at the workplace since the onset of the pandemic in SSA. Questions were regarding provisions at the workplace that would prevent them from acquiring infection and workplace training, management, and handling options for suspected COVID-19 patients. All questions elicited yes or no answers. Correct answers were scored 1 point, and the incorrect/unknown answer was 0 points. Each individual's total score ranged between 0 and 10 , with a high score indicating a high level of COVID-19 prevention measures. ${ }^{23-26}$

The questionnaire also assessed mental health and wellbeing, including social stigma and psychological stress. ${ }^{27}$ Psychological distress was measured over the past 2 weeks using the four-item Patient Health Questionnaire for Depression and Anxiety Scale (PHQ-4), with a total score ranging from 0 to 12. The scores of 2, 5, 8, and 9 are the cut-off points for none, mild, moderate, and severe psychological stress, respectively. The anxiety and depression subscales are the sums of the first and the last two questions of the PHQ-4, respectively, with a total score ranging from 0 to 6 . On each subscale, a score of 3 or above was considered positive for anxiety and depression screening purposes. ${ }^{27}$

Descriptive analyses were conducted; means and SDs are presented for continuous variables, medians and interquartile ranges are presented for skewed variables, and counts and percentages are presented for categorical variables. Using the aggregated scores, knowledge, perception, and preventive practices were dichotomized. Factors associated with adequate knowledge, correct perceptions, and high level of prevention measures were identified by running modified Poisson regression models. Modified Poisson regression analysis was conducted using demographic characteristics including country of residence, facility managing authority, whether the HCP had treated COVID-19 patients, and availability of workplace guidelines as independent variables and adequate knowledge, correct perceptions, and high levels of prevention measures as outcome variables. Crude risk ratios (CRRs) and adjusted risk ratios (ARRs) were calculated with 95\% confidence intervals (Cls). All data were managed and analyzed using Stata version 16. Variables that were significant in the univariate analysis $(P<$ 0.2 ) were used to control for confounding for the final model. The level of statistical association used is $P<0.05$.

\section{RESULTS}

Sociodemographic characteristics of the HCPs. A total of $900 \mathrm{HCPs}$ participated in this phone survey, with 300 from each country. Most participants provided nursing care 
TABLE 1

Sociodemographic characteristics of healthcare providers in three sub-Saharan African countries

\begin{tabular}{|c|c|c|c|c|}
\hline & Burkina Faso & Ethiopia & Nigeria & \\
\hline Sociodemographic characteristics & Ouagadougou & Addis Ababa & Lagos and Ibadan & Total \\
\hline \multicolumn{5}{|c|}{ Type of healthcare provided, $N(\%)$} \\
\hline Medicine & $83(27.67)$ & $114(38.00)$ & $78(26.00)$ & $275(30.56)$ \\
\hline Nursing & 217 (72.33) & $183(61.00)$ & 220 (73.33) & $620(68.89)$ \\
\hline Other ${ }^{\#}$ & $0(0)$ & $3(1.00)$ & $2(0.67)$ & $5(0.56)$ \\
\hline $\begin{array}{l}\text { Age, years, mean/median } \\
\text { (SD/range) }\end{array}$ & $39.73 / 37.50$ (9.91/25-75) & $34.40 / 30.00$ (10.53/21-72) & $45.18 / 45.00(9.09 / 23-77)$ & $39.77 / 39.00(10.79 / 21-77)$ \\
\hline \multicolumn{5}{|l|}{$\operatorname{Sex}, N(\%)$} \\
\hline Male & $157(52.33)$ & $141(47.00)$ & 74 (24.67) & $372(41.33)$ \\
\hline Female & $143(47.67)$ & 159 (53.00) & 226 (75.33) & 528 (58.67) \\
\hline \multicolumn{5}{|l|}{ Occupation, $N(\%)$} \\
\hline Doctor & $81(27.00)$ & $120(40.00)$ & 77 (25.67) & $278(30.89)$ \\
\hline Nurse and Other* & $219(73.00)$ & $180(60.00)$ & $223(74.00)$ & $622(69.11)$ \\
\hline \multicolumn{5}{|l|}{ Facility, $N(\%)$} \\
\hline Government hospital/clinic & $161(53.67)$ & $211(70.33)$ & 256 (85.33) & $627(69.67)$ \\
\hline Private hospital/clinic & $71(23.67)$ & $89(29.67)$ & $44(14.67)$ & $205(22.78)$ \\
\hline Other $\$$ & $68(22.67)$ & $0(0)$ & $0(0)$ & $68(7.56)$ \\
\hline \multicolumn{5}{|c|}{ Treated COVID-19 patients, $N(\%)$} \\
\hline Yes & $41(13.67)$ & $192(64.00)$ & $130(43.62)$ & $365(40.56)$ \\
\hline No & 259 (86.33) & $108(36.00)$ & $168(56.38)$ & 535 (59.44) \\
\hline
\end{tabular}

(72\% in Burkina Faso, 61\% in Ethiopia, and 73\% in Nigeria). Participants' average age was 40, 34, and 45 years, respectively, for Burkina Faso, Ethiopia, and Nigeria. Male healthcare providers accounted for around half of those surveyed in Burkina Faso (52\%) and Ethiopia (47\%), whereas they accounted for one-fifth in Nigeria. Approximately one-fifth of the HCPs in Burkina Faso worked in health outposts and clinics, whereas all participants in Ethiopia and Nigeria either worked in governmental or private hospitals (Table 1)

Knowledge of COVID-19. Most participants in Burkina Faso (95\%), Ethiopia (77\%), and Nigeria (99\%) were concerned about the pandemic. Even though most of the survey participants recognized the major symptoms of COVID-19, fewer recognized skin rash as one of the symptoms. Almost

TABLE 2

COVID-19 knowledge among Healthcare Providers in three sub-Saharan African countries

\begin{tabular}{|c|c|c|c|c|}
\hline & Burkina Faso & Ethiopia & Nigeria & \\
\hline Provider knowledge & Ouagadougou & Addis Ababa & Lagos and Ibadan & Total \\
\hline Concerned about COVID-19, ${ }^{*} N(\%)$ & $284(94.67)$ & $230(76.67)$ & $297(99.00)$ & $811(90.11)$ \\
\hline \multicolumn{5}{|l|}{ Knew the main symptoms of COVID- $19,{ }^{*} N(\%)$} \\
\hline Weakness & $273(91.00)$ & $295(98.33)$ & $290(96.67)$ & $858(95.33)$ \\
\hline Fever & $293(97.67)$ & $297(99.00)$ & $292(97.33)$ & $882(98.00)$ \\
\hline Dry cough & $292(97.33)$ & $298(99.33$ & $296(98.67)$ & $886(98.44)$ \\
\hline \multicolumn{5}{|l|}{ Knew less common symptoms of COVID-19* } \\
\hline Sore throat & 274 (91.33) & 295 (98.33) & $296(98.67)$ & $865(96.11)$ \\
\hline Headache & $258(86.00)$ & $288(96.00)$ & $225(75.00)$ & $771(85.67)$ \\
\hline Runny nose & $252(84.00)$ & $206(68.67)$ & 232 (77.33) & $690(76.67)$ \\
\hline Skin rash & $56(18.6)$ & $89(29.67)$ & $57(19.00)$ & $202(22.44)$ \\
\hline Muscle and joint aches & $239(79.67)$ & 286 (95.33) & 268 (89.33) & $793(88.11)$ \\
\hline Loss of smell & $237(79.00)$ & $269(89.67)$ & $293(97.67)$ & $799(88.78)$ \\
\hline \multicolumn{5}{|l|}{ Knew severe symptoms of COVID-19, ${ }^{*} N(\%)$} \\
\hline Shortness of breath & $265(88.33)$ & $296(98.67)$ & $294(98.00)$ & $855(95.00)$ \\
\hline \multicolumn{5}{|l|}{ Knew transmission methods of COVID-19, ${ }^{*} N(\%)$} \\
\hline Respiratory droplets & $293(97.67)$ & $296(98.67)$ & $291(97.00)$ & $880(97.78)$ \\
\hline Objects and surfaces & $290(96.67)$ & 297 (99.00) & $292(97.33)$ & $879(97.67)$ \\
\hline Physical contact & $283(94.33)$ & $294(98.00$ & 292 (97.33) & $869(96.56)$ \\
\hline \multicolumn{5}{|c|}{ Correctly identified false transmission methods of COVID-19, ${ }^{*} N(\%)$} \\
\hline Mosquito bites & $294(98.0)$ & $244(81.33)$ & $273(91.00)$ & $811(90.11)$ \\
\hline Cellular mobile networks & $292(97.33)$ & $290(96.67)$ & $240(80.00)$ & $822(91.33)$ \\
\hline Aggregated mean knowledge score (ranges: $0-15)$, mean (SD) & $12.97(1.69)$ & $13.46(1.19)$ & $13.10(1.20)$ & $13.18(1.39)$ \\
\hline Total Mean knowledge score $\dagger$ & $0.86(0.11)$ & $0.90(0.08)$ & $0.87(0.08)$ & $0.88(0.09)$ \\
\hline \multicolumn{5}{|l|}{ Knowledge status } \\
\hline Adequate & $213(71.00)$ & $248(82.67)$ & $218(72.67)$ & $679(75.44)$ \\
\hline Moderate/poor & $87(29.00)$ & $52(17.33)$ & $82(27.33)$ & $221(24.56)$ \\
\hline
\end{tabular}

Number of observations (percentage).

† Mean/median (SD/range). 
all were knowledgeable about the methods of COVID-19 transmission. The aggregated mean knowledge scores (out of 15) in Burkina Faso, Ethiopia, and Nigeria were 12.97, 13.46, and 13.1, respectively (Table 2).

Perceptions of COVID-19. About $45 \%, 28 \%$, and $29 \%$ of the participants in Burkina Faso, Ethiopia, and Nigeria, respectively, perceived a very high risk of contracting COVID-19, with $80 \%$ across all countries perceiving a high or very high risk. Almost all participants in each country had correct perceptions of prevention and transmission methods of COVID-19. Most HCPs in Burkina Faso believed "most COVID-19 patients die, but some survive," whereas half of the Ethiopian and Nigerian HCPs did not believe so. The aggregated mean perception score in Burkina Faso was 9.38, compared with 8.43 in Ethiopia and 8.12 in Nigeria. Eighty-six percent of the HCPs in Burkina Faso had a correct perception level, compared with half in Ethiopia and 35\% in Nigeria (Table 3).

COVID-19 prevention measures. Nearly all participants self-reported regularly wearing masks, using sanitizers and washing stations, washing their hands, and cleaning and decontaminating in their respective facilities, and most reported wearing personal protective equipment. A significant portion of the HCPs (73\%) in Nigeria had previously treated COVID-19 patients at their workplace, compared with onefifth of the HCPs in Burkina Faso and half of the HCPs in Ethiopia. Eighty-three percent of the HCPs in Burkina Faso, 61\% in Ethiopia, and $98 \%$ in Nigeria had workplace guidelines for COVID-19. Most participants (62\% in Burkina Faso, $68 \%$ in Ethiopia, and $89 \%$ in Nigeria) received training on the disease's natural course. Healthcare providers in Nigeria had higher aggregated mean levels of COVID-19 prevention measures compared with Burkina Faso and Ethiopia. In Nigeria, $82 \%$ had high levels of prevention measures, compared with $50 \%$ in Ethiopia and 39\% in Burkina Faso (Table 4).

Mental health and well-being. The majority of the participants $(88.4 \%)$ reported they did not drink alcohol, and $64.1 \%$ reported no change in sleeping habits since the start of the pandemic. Most HCPs in Burkina Faso (59\%) and Nigeria (86\%) experienced social acknowledgment, whereas only $25 \%$ in Ethiopia did. A smaller proportion of Ethiopian participants (1.7\%) reported violence against $\mathrm{HCPs}$, whereas $5 \%$ and $7 \%$ of the participants in Burkina Faso and Nigeria did. Even though only a small proportion of participants reported physical violence and service denial, most perceived social stigma toward HCPs, with $88 \%$ of HCPs in Ethiopia reporting social stigma. Based on the aggregated psychological stress score, $82 \%$ had no psychological distress (Table 5).

Factors associated with adequate knowledge of COVID-19 among HCPs. Ethiopian HCPs were $12 \%$ more likely (ARR: 1.12; $95 \% \mathrm{Cl}: 1.02-1.25)$ to have adequate knowledge of COVID-19 compared with HCPs from Burkina Faso. Compared with doctors, nursing practitioners were $17 \%$ less likely to have adequate COVID-19 knowledge (ARR: 0.83; 95\% Cl: $0.77-0.90)$. Healthcare poviders working in government facilities were not different from those working at private clinics with respect to having adequate knowledge. Similarly, there was no difference between male and female HCPs, and age was not a significant predictor of knowledge (Table 6).

Factors associated with a correct perception of COVID19 among HCPs. Most variables had a statistically significant association with correct perceptions of the COVID-19

TABLE 3

COVID-19 Perceptions of Healthcare Providers in three sub-Saharan African countries

\begin{tabular}{|c|c|c|c|c|}
\hline \multirow[b]{2}{*}{ Provider perceptions } & \multirow{2}{*}{$\frac{\text { Burkina Faso }}{\text { Ouagadougou }}$} & \multirow{2}{*}{$\frac{\text { Ethiopia }}{\text { Addis Ababa }}$} & Nigeria & \multirow[b]{2}{*}{ Total } \\
\hline & & & Lagos and Ibadan & \\
\hline \multicolumn{5}{|l|}{ Perceived level of risk for COVID-19, $N(\%)$} \\
\hline No risk & $1(0.30)$ & $4(1.33)$ & $4(1.33)$ & $9(1.00)$ \\
\hline Low risk & $61(20.3)$ & $51(17.00)$ & $42(14.00)$ & $154(17.11)$ \\
\hline High risk & $104(34.67$ & $161(53.67)$ & $166(53.33)$ & $431(47.89)$ \\
\hline Very high & $134(44.67)$ & $83(27.67)$ & $88(29.33)$ & $305(33.89)$ \\
\hline \multicolumn{5}{|l|}{ Ways to prevent transmission of COVID-19, $N(\%)$} \\
\hline Staying at home & $271(90.33)$ & 298 (99.33) & $270(90.00)$ & $839(93.22)$ \\
\hline Socially distancing & 296 (98.67) & $300(100.00)$ & 295 (98.33) & 891 (99.00) \\
\hline Regular washing hands & 297 (99.00) & $300(100.00)$ & 297 (99.00) & 894 (99.33) \\
\hline Sanitizing & 297 (99.00) & $300(100.00)$ & 294 (98.00) & $891(99.00)$ \\
\hline Covering cough and sneeze & 299 (99.67) & $298(99.33)$ & 297 (99.00) & 894 (99.33) \\
\hline Wearing a mask & 299(99.34) & 296 (98.67) & 298 (99.33) & $892(99.11)$ \\
\hline \multicolumn{5}{|l|}{$\begin{array}{l}\text { Myths about ways to prevent COVID-19, N (\% with } \\
\text { correct answer) }\end{array}$} \\
\hline Sun exposure & $278(92.67)$ & $182(60.67)$ & $199(66.33$ & $659(73.22)$ \\
\hline Drinking alcohol & 295(98.83) & 283 (94.33) & 275 (91.67) & $853(94.78)$ \\
\hline Lemon or ginger eat & $276(92.00)$ & $167(55.67)$ & 130 (43.33) & $573(63.67)$ \\
\hline Vitamin supplements & 207 (69.00) & $105(35.00)$ & $83(27.67)$ & $395(43.89)$ \\
\hline \multicolumn{5}{|l|}{ Severity of COVID-19, N (\%) } \\
\hline Everyone dies 2-4 weeks & $1(0.33)$ & $6(2.00)$ & $0(0.00)$ & $7(0.78)$ \\
\hline Some survive, most die & $3(1.00)$ & $23(7.67)$ & $51(14.00)$ & 77 (8.56) \\
\hline Most survive, some die & $274(91.33)$ & $244(81.33)$ & 213(53.33) & $731(81.22)$ \\
\hline Almost everyone survives & $21(7.00)$ & $26(8.67)$ & 24 (29.33) & $71(7.89)$ \\
\hline Do not know/refusal & $1(0.33)$ & $1(0.33)$ & $12(4.00)$ & $14(1.55)$ \\
\hline \multicolumn{5}{|l|}{ Aggregated mean perception score (range: 0-10) } \\
\hline Mean (SD) & $9.38(0.82)$ & $8.43(1.13)$ & $8.13(1.19)$ & $8.64(1.18)$ \\
\hline Total mean perception score, mean/median (SD/range) & $0.94(0.08)$ & $0.84(0.11)$ & $0.81(0.12)$ & $0.86(0.12)$ \\
\hline \multicolumn{5}{|l|}{ Perception status, $N(\%)$} \\
\hline Positive & $257(85.67)$ & $150(50.00)$ & $104(34.67)$ & $511(56.78)$ \\
\hline Negative & 43 (14.33) & $150(50.00)$ & 196 (65.33) & 389 (43.22) \\
\hline
\end{tabular}


TABLE 4

Preventive measures available in the workplaces of healthcare providers in three sub-Saharan African countries

\begin{tabular}{|c|c|c|c|c|c|}
\hline & & Burkina Faso & Ethiopia & Nigeria & \\
\hline & & Ouagadougou & Addis Ababa & Lagos and Ibadan & Total \\
\hline \multirow{6}{*}{$\begin{array}{l}\text { COVID-19 Preventive } \\
\text { measures* }\end{array}$} & Wearing mask & $300(100)$ & 298 (99.33) & 295 (98.33) & $893(99.22)$ \\
\hline & Wearing PPE & $255(85.00)$ & 267 (89.00) & 250 (83.33) & $772(85.78)$ \\
\hline & Handwashing with water and soap & $296(98.67)$ & $293(97.67)$ & 298 (99.33) & $887(98.56)$ \\
\hline & Sufficient distance between patients & $276(92.00)$ & $246(82.00)$ & 280 (93.33) & $802(89.11)$ \\
\hline & $\begin{array}{l}\text { Presence of sanitizers and handwashing } \\
\text { station }\end{array}$ & $287(95.67)$ & $278(92.67)$ & $297(99.00)$ & $862(95.78)$ \\
\hline & Regular cleaning and decontamination & $276(92.00)$ & $282(94.0)$ & $293(9767)$ & $851(94.56)$ \\
\hline \multirow{4}{*}{$\begin{array}{l}\text { COVID-19 training or } \\
\text { formal orientation } \\
\text { COVID-19* }\end{array}$} & The natural course of COVID-19 disease & 187 (62.33) & $203(67.67)$ & 266 (88.67) & 656 (72.89) \\
\hline & $\begin{array}{l}\text { Management and treatment of the } \\
\text { disease, }\end{array}$ & $133(44.33)$ & 201 (67.00) & 258 (86.00) & $592(65.78)$ \\
\hline & $\begin{array}{l}\text { Management health conditions with } \\
\text { COVID-19 }\end{array}$ & $130(43.33)$ & 175 (58.33) & 257 (85.67) & $562(62.44)$ \\
\hline & $\begin{array}{l}\text { Available options for suspected patients } \\
\text { of COVID-19 }\end{array}$ & $150(50.00)$ & $182(60.67)$ & 259 (86.33) & $599(66.56)$ \\
\hline $\begin{array}{l}\text { Presence of } \\
\text { guidance on } \\
\text { COVID-19* }\end{array}$ & & 249 (83.0) & $182(60.67)$ & 295 (98.33) & 726 (80.67) \\
\hline Action to be taken if & Refer to another facility & 185 (74.30)‡ & $67(36.81) \S$ & $79(26.28) \|$ & $331(45.59)$ \\
\hline COVID-19 & Treat at the facility & $60(24.10)$ & $93(51.10)$ & $216(73.22)$ & $369(50.83)$ \\
\hline diagnosed* & Send home & $4(1.61)$ & 22 (12.09) & $0(0)$ & $26(3.58)$ \\
\hline $\begin{array}{l}\text { Preventive measure } \\
\text { score }\end{array}$ & Range: 0 to 10 & 7.63 (1.92) & $8.11(2.06)$ & $9.18(1.42)$ & 8.31 (1.93) \\
\hline $\begin{array}{l}\text { Mean preventive } \\
\text { measure score } †\end{array}$ & Total mean & $0.80(0.17)$ & $0.84(0.18)$ & $0.92(0.12)$ & $0.85(0.17)$ \\
\hline Preventive measure & High & $118(39.33)$ & $167(55.67)$ & $246(82.00)$ & $531(59.00)$ \\
\hline status* $^{*}$ & Low & $182(60.67)$ & 133 (44.33) & $54(18.00)$ & 369 (41.00) \\
\hline
\end{tabular}

$\mathrm{PPE}=$ personal protective equipment.

$\mathrm{SD}=$ standard deviation.

*Number of observations (percentage).

$\dagger$ Mean/median (SD/range).

$\ddagger 249$ observations.

$\S 182$ observations.

|| 295 observations.

pandemic in the univariate analysis. Compared with the HCPs in Burkina Faso, those in Ethiopia (ARR: 0.57; 95\% Cl: 0.49-0.66) and Nigeria (ARR: 0.43; 95\% Cl: 0.36-0.51) were less likely to have correct perceptions of COVID-19. Nurses and other HCPs were 18\% less likely (ARR: $0.82 ; 95 \% \mathrm{Cl}$ : 0.73-0.92) to have correct perceptions compared with doctors. In adjusted models, HCPs who had treated COVID-19 patients had no difference in risk (ARR: 1.02; $95 \% \mathrm{Cl}$ : 0.89-1.17) for correct perception compared with those who had not treated COVID-19 patients. Healthcare providers with workplace guidelines were $10 \%$ less likely to have correct perception than their counterparts, but this relationship was not statistically significant (ARR: $0.90 ; 95 \% \mathrm{Cl}$ : 0.79-1.02). All variables, except country and occupation, were not statistically significantly associated with correct perception (Table 7).

Factors associated with high levels of COVID-19 prevention measures among HCPs. In the final analysis, factors associated with high COVID-19 preventive measures were country, treating COVID-19 patients, and the presence of workplace guidelines. Study participants were more likely to have high levels of prevention measures than their counterparts if they had treated COVID-19 patients (ARR: 1.37; 95\% Cl: 1.23-1.53) or had guidelines regarding COVID-19 in their workplace (ARR: 1.65; 95\% Cl: 1.34-2.02). Healthcare providers working in governmental institutions were $21 \%$ more likely (ARR: 1.21; 95\% Cl: 0.84-1.75) to have high levels of prevention measures than those working in health outposts and clinics. Healthcare providers in Nigeria were $78 \%$ more likely to have high preventive measures (ARR 1.78; $95 \% \mathrm{Cl}$ : 1.49-2.12) compared with those in Burkina Faso (Table 8).

\section{DISCUSSION}

We found that about three-fourths of HCPs had an adequate level of knowledge, and more than half had correct perceptions and high levels of prevention measures related to COVID-19. The majority of the HCPs perceived social stigma due to COVID-19. However, most were not experiencing depression, anxiety, or psychological distress. Occupation was a predictor of having adequate knowledge of COVID-19. The HCPs' country was associated with both adequate knowledge and correct perceptions; the participant's occupation was also associated with correct perceptions toward COVID-19. Healthcare providers with experience treating COVID-19 patients had higher levels of COVID-19 prevention measures.

Most participants could correctly identify the most common and severe symptoms of COVID-19 and the virus's transmission methods. However, fewer participants could identify skin rash and runny nose as less common symptoms of COVID-19. This finding highlights that health authorities should continue to encourage HCPs to access information from reliable sources and educational courses focusing on less common presentation and management of COVID-19. ${ }^{28}$ Even though participants practicing nursing were less likely to be knowledgeable than physicians, the average knowledge score was still $87 \%$, indicating a high level of COVID-19 knowledge among HCPs. The high level of knowledge could be due to a 
TABLE 5

Healthcare provider mental health and wellbeing during COVID-19 in three sub-Saharan African countries

\begin{tabular}{|c|c|c|c|c|c|}
\hline & & Burkina Faso & Ethiopia & Nigeria & \\
\hline & & Ouagadougou & Addis Ababa & Lagos and Ibadan & Total \\
\hline \multirow[t]{4}{*}{ Alcohol drinking habits* } & Do not drink alcohol & 229 (76.33) & 238 (79.30) & $284(94.67)$ & $751(88.44)$ \\
\hline & Drank less & $33(11.00)$ & $38(12.67)$ & $12(4.00)$ & $83(9.22)$ \\
\hline & Drank same & $36(12.00)$ & $19(6.33)$ & $4(1.33)$ & $59(6.56)$ \\
\hline & Drank more & $2(0.67)$ & $5(1.67)$ & $0(0)$ & $7(0.78)$ \\
\hline \multirow[t]{3}{*}{ Sleeping habits* } & Sleep less & 97 (32.33) & 40 (13.33) & 49 (16.33) & $186(20.67)$ \\
\hline & Sleep the same & 176 (58.67) & $202(67.33)$ & $198(66.00)$ & $577(64.11)$ \\
\hline & Sleep better & $27(9.00)$ & $57(17.67)$ & $53(17.67)$ & $137(15.22)$ \\
\hline \multirow[t]{5}{*}{ Perceived stigma* } & Social avoidance or rejection & 108 (35.88) & $131(43.67)$ & 175 (58.33) & $414(46.00)$ \\
\hline & Denial of services & $9(2.99)$ & $45(15.00)$ & $11(3.67)$ & $65(7.22)$ \\
\hline & Physical violence & $16(5.32)$ & $5(1.67)$ & $22(7.33)$ & $43(4.78)$ \\
\hline & No Acknowledgment & $123(41.00)$ & $225(75.00)$ & $42(14.00)$ & $390(43.33)$ \\
\hline & Perceived Stigma (aggregated) & $198(66.00)$ & $263(87.67)$ & $202(67.33)$ & 663 (73.67) \\
\hline \multirow[t]{4}{*}{ Feeling nervous, anxious, or on edge ${ }^{\star}$} & Not at all & $215(71.17)$ & $256(85.33)$ & 217 (72.33) & 688 (76.44) \\
\hline & Several days & $26(8.67)$ & $17(5.67)$ & $42(14.00)$ & 85 (9.44) \\
\hline & More than half the days & $44(14.67)$ & $18(6.00)$ & $36(12.00)$ & 98 (10.89) \\
\hline & Nearly every day & $15(5.00)$ & $9(3.00)$ & $5(1.67)$ & $29(3.22)$ \\
\hline \multirow{4}{*}{$\begin{array}{l}\text { Not being able to halt or } \\
\text { control worrying* }\end{array}$} & Not at all & $235(78.33)$ & $272(90.67)$ & $231(77.00)$ & $738(82.00)$ \\
\hline & Several days & $18(6.00)$ & $10(3.33)$ & $36(12.00)$ & $64(7.11)$ \\
\hline & More than half the days & 38 (12.67) & $15(5.00)$ & $30(10.00)$ & $83(9.22)$ \\
\hline & Nearly every day & $9(3.00)$ & $3(1.00)$ & $3(1.00)$ & $15(1.67)$ \\
\hline \multirow[t]{4}{*}{ Feeling down, depressed or hopeless* } & Not at all & 233 (77.67) & $278(92.67)$ & 262 (87.33) & 773 (85.89) \\
\hline & Several days & $20(6.67)$ & $12(4.00)$ & $28(9.33)$ & $60(6.67)$ \\
\hline & More than half the days & 37 (12.33) & $7(2.33)$ & $8(2.67)$ & 52 (5.78) \\
\hline & Nearly every day & $10(3.33)$ & $3(1.00)$ & $2(0.67)$ & $15(1.67)$ \\
\hline \multirow[t]{4}{*}{ Little interest or pleasure in doing things* } & Not at all & $272(90.7)$ & $266(88.67)$ & $269(89.67)$ & $807(89.67)$ \\
\hline & Several days & $6(2.00)$ & $18(6.00)$ & $23(7.67)$ & $47(5.22)$ \\
\hline & More than half the days & $17(5.67)$ & $5(1.67)$ & $4(1.33)$ & $26(2.89)$ \\
\hline & Nearly every day & $5(1.67)$ & $11(3.67)$ & $4(1.33)$ & $20(2.22)$ \\
\hline Psychological distress score $†$ & Total score: 12 & $1.53(2.34)$ & $0.75(1.76)$ & $1.09(1.97)$ & $1.12(2.06)$ \\
\hline Anxiety ${ }^{*}$ & & 40 (13.33) & $6(2.00)$ & $13(4.33)$ & $59(6.56)$ \\
\hline Depression* & & $29(9.67)$ & $18(6.00)$ & $12(4.00)$ & $59(6.56)$ \\
\hline \multirow[t]{4}{*}{ Psychological distress* } & None & $232(77.33)$ & $262(87.33)$ & $243(81.00)$ & $737(81.89)$ \\
\hline & Mild & 41 (13.67) & $30(10.00)$ & 46 (15.33) & $117(13.00)$ \\
\hline & Moderate & $23(7.67)$ & 5 (1.67) & $8(2.67)$ & $36(4.00)$ \\
\hline & Severe & $4(1.33)$ & $3(1.00)$ & $3(1.00)$ & $10(1.11)$ \\
\hline
\end{tabular}

* Number of observations (percentage)

$\dagger$ Mean/median (SD/range).

high proportion of HCPs $(73 \%)$ having received training and scientific information on COVID-19. In contrast, a webbased survey in India reported that most HCPs (61\%) used social media as a source of information and found that HCPs had poor knowledge about COVID-19 transmission and symptom onset, although they had positive perceptions of COVID-19 prevention and control. ${ }^{29}$ Factors associated with insufficient knowledge and perceptions in this study were age and profession. Another multicenter study in Ethiopia reported that many HCPs had adequate knowledge and correct perceptions of COVID-19 and that using social media, telecommunication, and television/radio were significantly associated with higher knowledge. ${ }^{30}$ In addition, an online cross-sectional study conducted in Uganda identified factors such as higher age and consumption of news media that were significantly associated with knowledge. ${ }^{31}$

We found that around half of the HCPs had correct perceptions of COVID-19 and that $34 \%$ of the participants thought they were at very high risk of infection. Almost all of the respondents were willing to wash and sanitize their hands regularly, practice social distancing, and use facemasks to control the pandemic's transmission. These results suggest that most of the respondents were confident in protecting themselves and were aware that COVID-19 is very contagious.
Even though about $73.2 \%, 95 \%$, and $64 \%$ of the HCPs correctly answered that sunbathing, drinking alcohol or tea, and ginger were not strategies to relieve the symptoms of COVID-19, more than half (56.1\%) of them chose vitamin supplementation as a preventive strategy. Although vitamins and supplements boost the immune system for fighting any infection, there is no evidence in their efficacy for treating COVID$19 .^{32,33}$ Therefore, regular updating of scientific information through the official webpages of WHO and health ministries of the respective country is needed to provide HCPs with the most up-to-date scientific information. ${ }^{28}$

Even though most HCPs reported wearing masks, washing their hands, and having sufficient sanitizers and washing stations at their workplace, only three-fifths had high levels of COVID-19 prevention measures. The HCPs who worked in a facility with COVID-19 workplace guidelines and cared for COVID-19 patients were more likely to practice high levels of prevention measures than their counterparts. In other studies, the type of facility was important: for instance, HCPs working in governmental facilities in China were more likely to have guidelines or policies and treat COVID-19 with an adequate supply of personal protective equipment. ${ }^{15,34}$ However, health workers are at great risk of infection, as noted in a study from the United Kingdom that estimated the risk of contracting 
TABLE 6

Factors associated with adequate COVID-19 knowledge among healthcare providers in three sub-Saharan African countries

\begin{tabular}{|c|c|c|c|c|c|c|}
\hline & CRR & $95 \% \mathrm{Cl}$ & $P$ value & ARR & $95 \% \mathrm{Cl}$ & $P$ value \\
\hline \multicolumn{7}{|l|}{ Country } \\
\hline Burkina Faso & ref & & & ref & & \\
\hline Ethiopia & 1.16 & $1.10-2.76$ & $0.023^{\star \star}$ & 1.12 & $1.02-1.25$ & $0.027^{\star \star}$ \\
\hline Nigeria & 1.02 & $0.73-1.69$ & 0.62 & 1.02 & $0.91-1.14$ & 0.74 \\
\hline \multicolumn{7}{|l|}{ Sex } \\
\hline $\begin{array}{l}\text { Male } \\
\text { Female }\end{array}$ & $\begin{array}{c}1.03 \\
\text { ref }\end{array}$ & $0.95-1.11$ & 0.49 & $\begin{array}{r}0.97 \\
\text { ref }\end{array}$ & $0.89-1.05$ & 0.44 \\
\hline Age, year & 0.99 & $0.99-1.00$ & 0.17 & 1.00 & $0.99-1.00$ & 0.98 \\
\hline \multicolumn{7}{|l|}{ Occupation } \\
\hline Doctors & ref & & & ref & & \\
\hline Nurses \& Other & 0.44 & $0.30-0.65$ & $0.000^{\star *}$ & 0.83 & $0.77-0.90$ & $0.000^{\star \star}$ \\
\hline \multicolumn{7}{|l|}{ Facility } \\
\hline Government & 1.11 & $0.94-1.31$ & 0.22 & 1.03 & $0.86-1.24$ & 0.74 \\
\hline Private & 1.07 & $0.90-1.28$ & 0.44 & 0.961 & $0.79-1.16$ & 0.64 \\
\hline Others & ref & & & ref & & \\
\hline \multicolumn{7}{|c|}{ Treated COVID-19 patients } \\
\hline Yes & 1.04 & $0.97-1.12$ & 0.81 & 0.99 & $0.91-1.07$ & 0.73 \\
\hline No & ref & & & ref & & \\
\hline \multicolumn{7}{|c|}{ Workplace guidelines } \\
\hline Yes & 0.91 & $0.83-0.98$ & 0.036 & 0.93 & $0.85-1.02$ & 0.14 \\
\hline No & ref & & & ref & & \\
\hline
\end{tabular}

$\mathrm{CRR}=$ crude risk ratio; $\mathrm{ARR}=$ adjusted risk ratio

${ }^{\star \star}$ Significant at $P<0.005$

COVID-19 in frontline HCPs was 12 times more than the general community, ${ }^{35}$ highlighting the importance of continued training and provision of preventive supplies to keep frontline workers safe.

Even though HCPs reported the same sleeping pattern since the pandemic, about $46 \%$ and $43 \%$ experienced social avoidance and disapproval. Most of the HCPs perceived social stigma due to COVID-19. However, less than one-fifth showed signs of psychological distress, and only $7 \%$ scored positive for anxiety and depression. Although psychological morbidity was low in this study, psychological morbidity has been reported as higher in India and China; therefore, programs and policies are needed to keep the morbidity low. ${ }^{36,37}$ These results could reflect the smaller toll of the pandemic in SSA compared with other places.

The use of data from multiple sites across SSA and the use of phone-based surveys to enable remote data collection during the pandemic to avail fresh information are strengths of this study. It is important to note that the information collected in this study is from major urban areas of the countries included. Hence, it is uncertain whether the results may be generalizable to health care workers in each country overall, especially to

TABLE 7

Factors associated with correct perceptions towards COVID-19 among healthcare providers in three sub-Saharan African countries

\begin{tabular}{|c|c|c|c|c|c|c|}
\hline & CRR & $95 \% \mathrm{Cl}$ & $P$ value & ARR & $95 \% \mathrm{Cl}$ & $P$ value \\
\hline \multicolumn{7}{|l|}{ Country } \\
\hline Burkina Faso & ref & & & ref & & \\
\hline Ethiopia & 0.15 & $0.09-0.24$ & $0.000^{\star *}$ & 0.57 & $0.49-0.66$ & $0.000^{\star \star}$ \\
\hline Nigeria & 0.10 & $0.0-0.16$ & $0.000^{\star *}$ & 0.43 & $0.36-0.51$ & $0.000^{\star \star}$ \\
\hline \multicolumn{7}{|l|}{ Sex } \\
\hline $\begin{array}{l}\text { Male } \\
\text { Female }\end{array}$ & 1.34 & $1.20-1.50$ & $0.000^{\star *}$ & 1.09 & $0.98-1.22$ & 0.10 \\
\hline Age, year & 0.99 & $0.99-1.00$ & 0.81 & 1.00 & $0.99-1.01$ & 0.98 \\
\hline \multicolumn{7}{|l|}{ Occupation } \\
\hline Doctors & ref & & & ref & & \\
\hline Nurses \& Other & 0.81 & $0.73-0.91$ & $0.001^{\star \star}$ & 0.82 & $0.73-0.92$ & $0.001^{\star \star}$ \\
\hline \multicolumn{7}{|l|}{ Facility } \\
\hline Government & 0.59 & $0.53-0.66$ & $0.000^{\star *}$ & 0.94 & $0.85-1.05$ & 0.31 \\
\hline Private & 0.68 & $0.59-0.78$ & $0.00^{\star *}$ & 0.94 & $0.82-1.08$ & 0.38 \\
\hline Others & ref & & & ref & & \\
\hline \multicolumn{7}{|c|}{ Treated COVID-19 patients } \\
\hline $\begin{array}{l}\text { Yes } \\
\text { No }\end{array}$ & $\begin{array}{c}1.04 \\
\text { ref }\end{array}$ & $0.76-0.98$ & $0.02^{\star *}$ & $\begin{array}{c}1.02 \\
\text { ref }\end{array}$ & $0.89-1.17$ & 0.81 \\
\hline \multicolumn{7}{|c|}{ Workplace guidelines } \\
\hline $\begin{array}{l}\text { Yes } \\
\text { No }\end{array}$ & $\begin{array}{c}0.86 \\
\text { ref }\end{array}$ & $0.76-0.98$ & $0.03^{\star \star}$ & $\begin{array}{c}0.90 \\
\text { ref }\end{array}$ & $0.79-1.02$ & 0.11 \\
\hline \multicolumn{7}{|l|}{ Perceived stigma } \\
\hline $\begin{array}{l}\text { Yes } \\
\text { No }\end{array}$ & $\begin{array}{c}0.81 \\
\text { ref }\end{array}$ & $0.57-1.16$ & 0.25 & $\begin{array}{c}0.92 \\
\text { ref }\end{array}$ & $0.84-1.04$ & 0.20 \\
\hline
\end{tabular}

${ }^{* \star}$ Significant at $P<0.005$. 
TABLE 8

Factors associated with high levels of prevention measures of healthcare providers towards COVID-19 in three sub-Saharan African countries

\begin{tabular}{|c|c|c|c|c|c|c|}
\hline & CRR & $95 \% \mathrm{Cl}$ & $P$ value & ARR & $95 \% \mathrm{Cl}$ & $P$ value \\
\hline \multicolumn{7}{|l|}{ Country } \\
\hline Burkina Faso & ref & & & ref & & \\
\hline Ethiopia & 1.42 & $1.19-1.68$ & $0.000^{\star \star}$ & 1.29 & $1.06-1.56$ & $0.011^{\star \star}$ \\
\hline Nigeria & 2.08 & $1.79-2.41$ & $0.000^{* *}$ & 1.78 & $1.49-2.12$ & $0.000^{\star *}$ \\
\hline \multicolumn{7}{|l|}{ Sex } \\
\hline $\begin{array}{l}\text { Male } \\
\text { Female }\end{array}$ & $\begin{array}{l}0.97 \\
\text { ref }\end{array}$ & $0.87-1.09$ & 0.63 & $\begin{array}{l}\text { NA } \\
\text { ref }\end{array}$ & NA & NA \\
\hline Age, year & 1.00 & $0.99-1.01$ & 0.19 & 1.00 & $0.99-1.00$ & 0.13 \\
\hline \multicolumn{7}{|l|}{ Occupation } \\
\hline Doctors & ref & & & ref & & \\
\hline Nurses \& Other & 0.97 & $0.87-1.09$ & 0.66 & NA & NA & NA \\
\hline \multicolumn{7}{|l|}{ Facility } \\
\hline Government & 1.98 & $1.42-2.78$ & $0.000^{\star *}$ & 1.21 & $0.84-1.75$ & 0.29 \\
\hline Private & 0.65 & $0.87-1.81$ & 0.23 & 0.91 & $0.62-1.33$ & 0.63 \\
\hline Others & ref & & & ref & & \\
\hline \multicolumn{7}{|c|}{ Treated COVID-19 patients } \\
\hline $\begin{array}{l}\text { Yes } \\
\text { No }\end{array}$ & $\begin{array}{c}1.54 \\
\text { ref }\end{array}$ & $1.38-1.71$ & $0.000^{\star \star}$ & $\begin{array}{l}1.37 \\
\text { ref }\end{array}$ & $1.23-1.53$ & $0.000^{\star *}$ \\
\hline \multicolumn{7}{|c|}{ Workplace guidelines } \\
\hline $\begin{array}{l}\text { Yes } \\
\text { No }\end{array}$ & $\begin{array}{c}1.85 \\
\text { ref }\end{array}$ & $1.50-2.27$ & $0.000^{\star \star}$ & $\begin{array}{l}1.65 \\
\text { ref }\end{array}$ & $1.34-2.02$ & $0.000^{\star *}$ \\
\hline \multicolumn{7}{|c|}{ Adequate Knowledge } \\
\hline $\begin{array}{l}\text { Yes } \\
\text { No }\end{array}$ & $\begin{array}{c}1.03 \\
\text { ref }\end{array}$ & $0.91-1.18$ & 0.58 & $\begin{array}{c}1.03 \\
\text { ref }\end{array}$ & $0.92-1.16$ & 0.58 \\
\hline \multicolumn{7}{|l|}{ Correct Perception } \\
\hline $\begin{array}{l}\text { Yes } \\
\text { No }\end{array}$ & $\begin{array}{l}0.84 \\
\text { ref }\end{array}$ & $0.76-0.94$ & $0.002^{\star \star}$ & $\begin{array}{l}1.10 \\
\text { ref }\end{array}$ & $0.99-1.22$ & 0.06 \\
\hline
\end{tabular}

${ }^{*}$ Significant at $P<0.005$.

those in rural areas. Furthermore, this study was a phonebased survey and therefore has the potential for introduction of selection bias because the report is based on only voluntary respondents.

Even though most HCPs in Burkina Faso, Ethiopia, and Nigeria had adequate knowledge of COVID-19, there is a need to improve COVID-19 perceptions and compliance with prevention measures. The level of knowledge, perception, and prevention measures regarding COVID-19 may differ in each country due to the caseload, epidemic curve, and the death toll in each country. An intersectoral approach is needed to combat COVID-19 in SSA to increase compliance with prevention measures and correct perceptions toward the virus. Due to the relatively moderate sample size and the cross-sectional design, further large-scale and longitudinal surveys or interventional studies are needed to understand further the long-term impacts of the COVID-19 pandemic on HCPs and the health systems in SSA. Because COVID-19 and its management are new phenomena to the world, potential factors that would affect knowledge acquisition and translation of knowledge to practices need to be studied from each country's perspective.

Received December 22, 2020. Accepted for publication February 20, 2021.

Published online June 24, 2021.

Acknowledgments: The authors thank the healthcare providers for sharing their experience in this phone survey. The American Society of Tropical Medicine and Hygiene has waived the Open Access fee for this article due to the ongoing COVID-19 pandemic.

Financial support: This work was supported by the Bill \& Melinda Gates Foundation (Grant OPP1179606) and by institutional support from the Heidelberg Institute of Global Health, Germany and the Harvard T.H. Chan School of Public Health, USA.
Authors' addresses: Nega Assefa, College of Health and Medical Sciences, Haramaya University, Harar, Ethiopia, E-mail: negaassefa@yahoo. com. Abdramane Soura and Bruno Lankoande, Institut Supérieur des Sciences de la Population, University of Ouagadougou, Ouagadougou, Burkina Faso, E-mails: asoura@issp.bf and blankoande@issp.bf. Elena Hemler, Michelle Korte, Dongqing Wang, Department of Global Health and Population, Harvard T.H. Chan School of Public Health, Harvard University, Boston, MA, E-mails: ehemler@hsph.harvard.edu, mkorte@ hsph.harvard.edu, and dqwang@hsph.harvard.edu. Yasir Younis Abdullahi, Jegula Hospital, Department of Obstetrics and Gynecology, Harar, Ethiopia, E-mail: yasdire@gmail.com. Ourohiré Millogo, Nouna Health Research Center, Nouna, Burkina Faso, E-mail: ourohire2001@ yahoo.fr. Angela Chukwu, Department of Statistics, University of Ibadan, Ibadan, Nigeria, E-mail: unnachuks2002@yahoo.co.uk. Firehiwot Workneh and Yemane Berhane, Addis Continental Institute of Public Health, Addis Ababa, Ethiopia, E-mails: firehiwotwaciph@ gmail.com and yemaneberhane@gmail.com. Ali Sie, Nouna Health Research Center, Nouna, Burkina Faso, E-mail: sieali@yahoo.fr. Till Baernighausen, Heidelberg Institute of Global Health, University of Heidelberg, Heidelberg, Germany, and Department of Global Health and Population, Harvard T.H. Chan School of Public Health, Harvard University, Boston, MA, E-mail: till.baernighausen@uni-heidelberg.de. Ayoade Oduola, University of Ibadan Research Foundation, University of Ibadan, Ibadan, Nigeria, E-mail: amjoduola@hotmail.com. Wafaie W. Fawzi, Departments of Global Health and Population, Epidemiology, and Nutrition, Harvard T.H. Chan School of Public Health, Harvard University, Boston, MA, E-mail: mina@hsph.harvard.edu.

This is an open-access article distributed under the terms of the Creative Commons Attribution (CC-BY) License, which permits unrestricted use, distribution, and reproduction in any medium, provided the original author and source are credited.

\section{REFERENCES}

1. $\mathrm{FMOH}, 2020$. National Comprehensive COVID19 Management Handbook. Addis Ababa: Ethiopia.

2. Paakkari L, Okan O, 2020. COVID-19: health literacy is an underestimated problem. Lancet Public Health 5: e249-e250. 
3. Sallam M, Dababseh D, Yaseen A, Al-Haidar A, Ababneh NA, Bakri FG, Mahafzah A, 2020. Conspiracy beliefs are associated with lower knowledge and higher anxiety levels regarding COVID-19 among students at the University of Jordan. Int $J$ Environ Res Public Health 17: 15-49.

4. Garrett L, 2020. COVID-19: the medium is the message. Lancet 395: 942-943.

5. Lammers J, Crusius J, Gast A, 2020. Correcting misperceptions of exponential coronavirus growth increases support for social distancing. Proc Natl Acad Sci USA 117: 16264-16266.

6. Ahonsi B, 2020. A research agenda on the sexual and reproductive health dimensions of the COVID-19 pandemic in Africa. Afr J Reprod Health 24: 22-25.

7. PeConga EK, Gauthier GM, Holloway A, Walker RSW, Rosencrans PL, Zoellner LA, Bedard-Gilligan M, 2020. Resilience is spreading: mental health within the COVID-19 pandemic. Psychol Trauma 12: S47-S48.

8. Africa Research Bulletin, 2020. HEALTH: coronavirus hotspots. Afr Res Bull Polit 57: 22819A-22820C. Available at: https:// doi.org/10.1111/j.1467-825X.2020.09585.X.

9. Worldometers, 2020. Coronavirus Update (Live). Available at: https://www.worldometers.info/coronavirus/?utm_campaign= homeAdvegas 1 ? $\% 22 \% 20 \% 5 \mathrm{Cl} \% 20 \% 22$ countries. Accessed October 18, 2020.

10. WHO, 2020. Coronavirus Disease (COVID-19) Weekly Epidemiological Update and Weekly Operational Update. Available at: https://www.who.int/emergencies/diseases/novel-coronavirus2019/situation-reports. Accessed August 17, 2020.

11. Shigute Z, Mebratie AD, Alemu G, Bedi A, 2020. Containing the spread of COVID-19 in Ethiopia. J Glob Health 10: 010369.

12. Wadvalla BA, 2020. How Africa has tackled COVID-19. BMJ 370: 28-30.

13. ICN, 2020. More than 600 Nurses Die from COVID-19 Worldwide. Available at: https://www.icn.ch/news/more-600-nurses-diecovid-19-worldwide. Accessed October 3, 2020.

14. WHO, 2020. Over 10000 Health Workers in Africa Infected with COVID-19. Available at: https://www.afro.who.int/news/over10-000-health-workers-africa-infected-covid-19. Accessed September 1, 2020.

15. Gan WH, Lim JW, Koh D, 2020. Preventing intra-hospital infection and transmission of coronavirus disease 2019 in health-care workers. Saf Health Work 11: 241-243.

16. Bhagavathula AS, Aldhaleei WA, Rahmani J, Mahabadi MA, Bandari DK, 2020. Knowledge and perceptions of COVID-19 among health care workers: cross-sectional study. JMIR Public Health Surveill 6: e19160.

17. WHO, 2020. Responding to COVID-19: Real-Time Training for the Coronavirus Disease Outbreak. Available at: https://openwho. org/channels/covid-19. Accessed September 1, 2020.

18. Darling AM et al., 2020. Design and field methods of the ARISE Network Adolescent Health Study. Trop Med Int Health 25: 5-14.

19. Kang $L$ et al., 2020. Impact on mental health and perceptions of psychological care among medical and nursing staff in Wuhan during the 2019 novel coronavirus disease outbreak: a crosssectional study. Brain Behav Immun 87: 11-17.

20. Ahmed S et al., Improving Health in Slums Collaborative, 2020. Impact of the societal response to COVID-19 on access to healthcare for non-COVID-19 health issues in slum communities of Bangladesh, Kenya, Nigeria and Pakistan: results of pre-COVID and COVID-19 lockdown stakeholder engagements. BMJ Glob Health 5: e003042.

21. Hemler EC, Korte M et al., 2021. Design and field methods of the ARISE Network COVID-19 Rapid Monitoring Survey. Am J Trop Med Hyg 105: 311-323.
22. Kebede Y, Yitayih Y, Birhanu Z, Mekonen S, Ambelu A, 2020. Knowledge, perceptions and preventive practices towards COVID-19 early in the outbreak among Jimma university medical center visitors, southwest Ethiopia. PLoS One 15: e0233744.

23. Erfani A, Shahriarirad R, Ranjbar K, Mirahmadizadeh A, Moghadami $M, 2020$. Knowledge, attitude and practice toward the novel coronavirus (COVID-19) outbreak: a population-based survey in Iran. Bull World Health Organ (E-pub ahead of print).

24. Zhong BL, Luo W, Li HM, Zhang QQ, Liu XG, Li WT, Li Y, 2020. Knowledge, attitudes, and practices towards COVID-19 among Chinese residents during the rapid rise period of the COVID-19 outbreak: a quick online cross-sectional survey. Int $J$ Biol Sci 16: $1745-1752$.

25. Ferdous MZ, Islam MS, Sikder MT, Mosaddek ASM, Zegarra-Valdivia JA, Gozal D, 2020. Knowledge, attitude, and practice regarding COVID-19 outbreak in Bangladesh: an online-based cross-sectional study. PLoS One 15: e0239254.

26. Goruntla N, Bhupalam P, Jinka DR, Thummala J, Dasari LY, Bonala KK, 2020. Knowledge, perception, and practices towards COVID-19 pandemic among general public of India: a cross-sectional online survey. Curr Med Res Pract 10: 153-159.

27. Xiao H, Shu W, Li M, Li Z, Tao F, Wu X, Yu Y, Meng H, Vermund $\mathrm{SH}, \mathrm{Hu} Y, 2020$. Social distancing among medical students during the 2019 coronavirus disease pandemic in China: disease awareness, anxiety disorder, depression, and behavioral activities. Int J Environ Res Public Health 17: 1-13.

28. Alrubaiee GG, Al-Qalah TAH, Al-Aawar MSA, 2020. Knowledge, attitudes, anxiety, and preventive behaviors towards COVID19 among health care providers in Yemen: an online crosssectional survey. BMC Public Health 201: 1541.

29. Bhagavathula AS, Aldhaleei WA, Rahmani J, Mahabadi MA, Bandari DK, 2020. Novel coronavirus (COVID-19) knowledge and perceptions: a survey of healthcare workers. medRxiv, 2020.03.09.20033381

30. Jemal B, Ferede ZA, Mola S, Hailu S, Abiy S, Wolde GD, Tilahun A, Tesfaye B, Lemma DT, Alimaw AA, 2021. Knowledge, attitude and practice of healthcare workers towards COVID-19 and its prevention in Ethiopia: a multicenter study. Patient Prefer Adherence 15: 337-348.

31. Olum R, Chekwech G, Wekha G, Nassozi DR, Bongomin F, 2020. Coronavirus disease-2019: knowledge, attitude, and practices of health care workers at Makerere University teaching hospitals, Uganda. Front Public Health 8: 181.

32. Sahebnasagh A, Saghafi F, Avan R, Khoshi A, Khataminia M, Safdari M, Habtemariam S, Ghaleno HR, Nabavi SM, 2020. The prophylaxis and treatment potential of supplements for COVID-19. Eur J Pharmacol 887: 173530.

33. Michienzi SM, Badowski ME, 2020. Can vitamins and/or supplements provide hope against coronavirus? Drugs Context 9: 5-7.

34. Lai $X$ et al., 2020. Will healthcare workers improve infection prevention and control behaviors as COVID-19 risk emerges and increases, in China? Antimicrob Resist Infect Control 9: 83.

35. Nguyen LH et al., 2020. Risk of COVID-19 among front-line healthcare workers and the general community: a prospective cohort study. Lancet Public Health 5: e475-e483.

36. Chatterjee SS, Bhattacharyya R, Bhattacharyya S, Gupta S, Das S, Banerjee BB, 2020. Attitude, practice, behavior, and mental health impact of COVID-19 on doctors. Indian J Psychiatry 62: $257-265$

37. Lai J et al., 2020. Factors associated with mental health outcomes among health care workers exposed to coronavirus disease 2019. JAMA Netw Open 3: e203976. 